\title{
Central pontine and extrapontine myelinolysis: report of a case with a tragic outcome
}

\author{
Adriana Rocha Brito, ${ }^{1}$ Marcio Moacyr Vasconcelos, ${ }^{2}$ Luiz Celso Hygino da Cruz Júnior, ${ }^{3}$ \\ Maria Emília Domingues Costa Quaresma de Oliveira, 4 \\ Adriana Rodrigues Miguel de Azevedo, 5 Luciana da Graça Vieira Rocha, 6 \\ Priscilla Costa Mendonça6
}

\begin{abstract}
Objective: To report a pediatric case of central pontine and extrapontine myelinolysis, a rare neurological disease often associated with rapid correction of hyponatremia.

Description: A 15 year-old female adolescent developed locked-in syndrome during severe hyponatremia. Brain magnetic resonance imaging was consistent with the diagnosis of central pontine and extrapontine myelinolysis.

Comments: Serum sodium correction should proceed slowly and cautiously, based upon a careful calculation of sodium deficit, in order to minimize metabolic stress and avoid the occurrence of this dreadful complication, which has a tragic outcome in most cases. There is no scientifically proved effective treatment for myelinolysis, and severe cases usually have a dismal prognosis.

J Pediatr (Rio J). 2006;82(2):157-60: Central pontine myelinolysis, extrapontine myelinolysis, osmotic demyelination, hyponatremia, magnetic resonance imaging, adolescence.
\end{abstract}

\section{Introduction}

Central pontine myelinolysis (CPM) is an acute demyelinating disease caused by rapidly fluctuating serum osmolality, resulting in symmetric demyelination within the central basis pontis. ${ }^{1-3}$ It occurs sporadically at all ages, ${ }^{3-5}$ equally affecting both males and females, and its precise incidence is unknown. 4

1. Mestranda em Pediatria, Hospital Universitário Antônio Pedro (HUAP), Universidade Federal Fluminense (UFF), Niterói, RJ, Brasil. Especialista em Neurologia Pediátrica, Instituto Fernandes Figueira (IFF), Fundação Oswaldo Cruz (FIOCRUZ), Rio de Janeiro, RJ, Brasil.

2. Professor adjunto, HUAP, UFF, Niterói, RJ, Brasil. Fellow, Children's Hospital, George Washington University, Washington, DC, EUA.

3. Médico radiologista, Clínica Multi-Imagem Ressonância Magnética, Rio de Janeiro, RJ, Brasil.

4. Médica residente, Serviço de Pediatria, HUAP, UFF, Niterói, RJ, Brasil.

5. Mestranda em Pediatria, HUAP, UFF, Niterói, RJ, Brasil. Especialista em Reumatologia Infantil, Instituto de Puericultura e de Pediatria Martagão Gesteira (IPPMG), Universidade Federal do Rio de Janeiro (UFRJ), Rio de Janeiro, RJ, Brasil.

6. Internas, Serviço de Pediatria, HUAP, UFF, Niterói, RJ, Brasil.

Manuscript received Aug 30 2005, accepted for publication Nov 092005.

Suggested citation: Brito $A B$, Vasconcelos MM, Cruz Júnior LC, Oliveira ME, Azevedo AR, Rocha LG, et al. Central pontine and extrapontine myelinolysis: report of a case with a tragic outcome. J Pediatr (Rio J). 2006;82:157-60.
Pontine lesions may be associated with extrapontine myelinolysis (EPM), which can symmetrically affect the cerebellar peduncles, caudate nucleus, putamen, frontal and temporal white matter, fornix, external and extreme capsules, claustrum, thalamus, subthalamic nucleus, internal capsule, amygdaloid nucleus, lateral geniculate nucleus, deep layers of the cerebral cortex, hippocampus and corpus callosum. 3,4,6-9

This disease has not been totally clarified yet, $1,2,5,9,10$ but it is usually associated with electrolytic disorders, especially severe hyponatremia and its rapid correction. 2,3,5,11-13 Some disorders seemingly predispose to this condition, such as liver failure, liver transplantation, pituitary tumor resection, severe burns, chronic renal failure, hemodialysis, lymphoma, carcinoma, malnutrition, severe bacterial infections, dehydration, electrolytic disorders (hyponatremia, hypernatremia, ${ }^{7}$ hyperglycemia, hypokalemia, 6 diabetes), acute hemorrhagic pancreatitis and chronic alcoholism, among others. 4,6,7,9,12

Its clinical course is characterized by quadriparesis (which is initially flaccid and later spastic), pseudobulbar palsy, acute mental status changes with depressed level 
of consciousness, coma, locked-in syndrome, and may lead to death. ${ }^{1-10,12-14}$ It often develops 2 to 7 days after correction of hyponatremia. 2,3,5,9,12 Ataxia $5,7,12$ is an uncommon symptom of CPM. ${ }^{14}$ Movement disorders, $3,5,6,12$ such as mutism, parkinsonism, dystonia, catatonia, among others, have been described.

Brain magnetic resonance imaging (MRI) is crucial to determine the extension of demyelination. Lesions are symmetric and hypointense on T1-weighted images, typically sparing the periphery of the pons and hyperintense on T2-weighted and FLAIR images. 2,3,5,6,9,10,12 In subacute and chronic phases, pontine lesions, mainly extrapontine ones, may become smaller in size and more clearlydefined. ${ }^{10}$ In some cases, MRI can show a pontine lesion with a typical batwing pattern. 4,9 Typical radiological findings are usually not seen on MRI in the first week after the onset of clinical symptoms. 2,5,9,14 Diffuse weighted images are promising for early diagnosis $2,3,6,9$ and can detect problems within the first 24 hours after the onset of quadriplegia. ${ }^{2}$

Histopathological findings reveal stripping of myelin sheaths, with sparing of axons and of the nerve cells of pontine nuclei, ${ }^{7,10}$ without evidence of inflammation. 1,2,4,12

The identification of at-risk patients is the first step in the treatment of myelinolysis. ${ }^{12}$ No specific treatment has been established. 5,15

The authors obtained an informed consent from the patient's father for publication of this study.

\section{Case report}

A previously healthy 15 -year-old female adolescent was admitted to the emergency room with diffuse abdominal pain, brown-colored urine, myalgias, intermittent fever, headache, and retro-orbital pain for the past 11 days. On admission, she had a serum sodium level of $110 \mathrm{mEq} / \mathrm{l}$ (normal: $135-145 \mathrm{mEq} / \mathrm{l}$ ). She was able to walk and could speak without difficulty. The following day, her serum sodium level dropped to $99 \mathrm{mEq} / \mathrm{l}$.

On the third hospital day, she had difficulty in walking associated with dysarthria, drowsiness, difficulty responding to verbal commands and gross hematuria. Her clinical status deteriorated within the following 24 hours, with intermittent level of consciousness and loss of walking ability.

On the fourth day, the patient had a serum sodium level of $102 \mathrm{mEq} / \mathrm{l}$, and sodium replacement was calculated in order to reach $125 \mathrm{mEq} / \mathrm{l}$ in only 6 hours. After 6.5 hours of correction, the serum sodium level rose to $115 \mathrm{mEq} / \mathrm{l}$, with continued replacement. After a 10-hour replacement period, her serum sodium level was $121 \mathrm{mEq} / \mathrm{l}$, i.e., there was an absolute increase of $19 \mathrm{mEq} / \mathrm{l}(1.9 \mathrm{mEq} / \mathrm{l} / \mathrm{h})$. The patient presented with stupor, hypotension, and hydroelectrolytic disorders and was then transferred to the intensive care unit, where she stayed for 2 days. Her clinical status partially improved, and preserved motor function was recorded on her medical chart. On the fifth day at hospital, the serum level of creatine phosphokinase (CPK) corresponded to $664 \mathrm{U} / \mathrm{L}$ (normal value: up to $55 \mathrm{U} / \mathrm{L})$.

On the tenth day, the patient presented with gradual loss of limb muscle strength, mutism, dysphagia and uncoordinated tongue movements, but she could understand all verbal requests, communicating with the examiner by moving her head.

On the 15th day, serum sodium level increased by $24 \mathrm{mEq} / \mathrm{l}$ within 23 hours after correction, reaching $144 \mathrm{mEq} / \mathrm{l}$. Serum CPK level reached a peak of 1,342 U/L, and afterwards averaged $140 \mathrm{U} / \mathrm{L}$. Cerebrospinal fluid test on the 17 th day revealed 1 cell $/ \mathrm{mm}^{3}$ with $100 \%$ lymphonuclear cells, a glucose level equal to $70 \mathrm{mg} / \mathrm{dl}$ and a protein level of $110 \mathrm{mg} / \mathrm{dl}$.

After 18 days in hospital, she was referred to another hospital (HUAP) for investigation. On admission, her neurological examination showed generalized flaccid muscle weakness, mutism, and inability to swallow, which characterized pseudobulbar palsy, intact sensitivity, isocoric and photoreactive pupils, preserved extrinsic ocular movement, spontaneous eye opening and appropriate responses by way of eye movements to all questions, being therefore diagnosed with locked-in syndrome.

Her brain MRI performed 11 days after correction of severe hyponatremia and on fifth day of neurological symptoms revealed symmetric and bilateral areas that were hypointense on T1-weighted images and hyperintense on T2-weighted and FLAIR images, with no contrast enhancement, located within the basal ganglia and pons (Figure 1).

The etiology of persistent hyponatremia was not clarified, but salt-wasting nephropathy was suspected because urinary sodium level was $158 \mathrm{mEq} / \mathrm{l}$, whereas serum sodium level was $113 \mathrm{mEq} / \mathrm{l}$ (normal value for urinary sodium $\leq 40 \mathrm{mEq} / \mathrm{l}$ ). Figure 2 shows the patient's serum levels of sodium. The patient also had occasional hypokalemia, with a minimum value of $2.3 \mathrm{mEq} / \mathrm{l}$. After 5 days, she had pneumonia and overt respiratory failure, necessitating ventilatory support and being transferred to the intensive care unit. The patient died from sepsis on the 12 th day after admission to the HUAP. Her family declined necropsy.

\section{Discussion}

CPM and EPM belong to the osmotic demyelination syndrome (ODS) 3,6,10,12 and are frequently related to the classic context of rapidly corrected hyponatremia, ${ }^{3-9,12,15}$ 

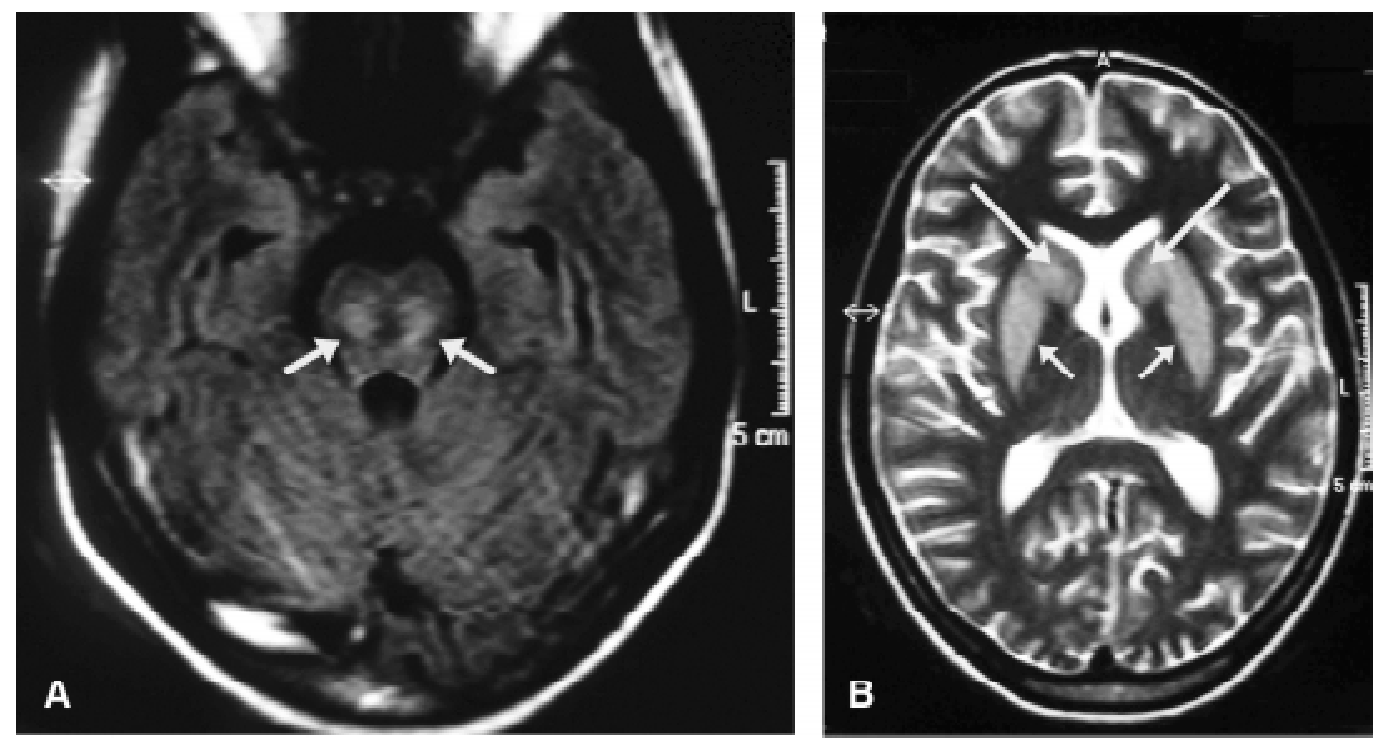

Figure 1 - Brain magnetic resonance imaging. A) Axial image using the FLAIR sequence within the basis pontis shows lesions caused by myelinolysis (white arrows). B) Axial T2-weighted image shows symmetric hyperintense and bilateral lesions to caudate nucleus (large arrows) and to putamen (small arrows)

especially in patients who have been chronically debilitated.2,10,11 Moreover, the initial intensity of hyponatremia and the corresponding absolute increase in final serum sodium levels also seem to play an important role in this dramatic prognosis. ${ }^{4,11}$ Nevertheless, ODS may occur when serum sodium levels are normal ${ }^{1,14}$ or

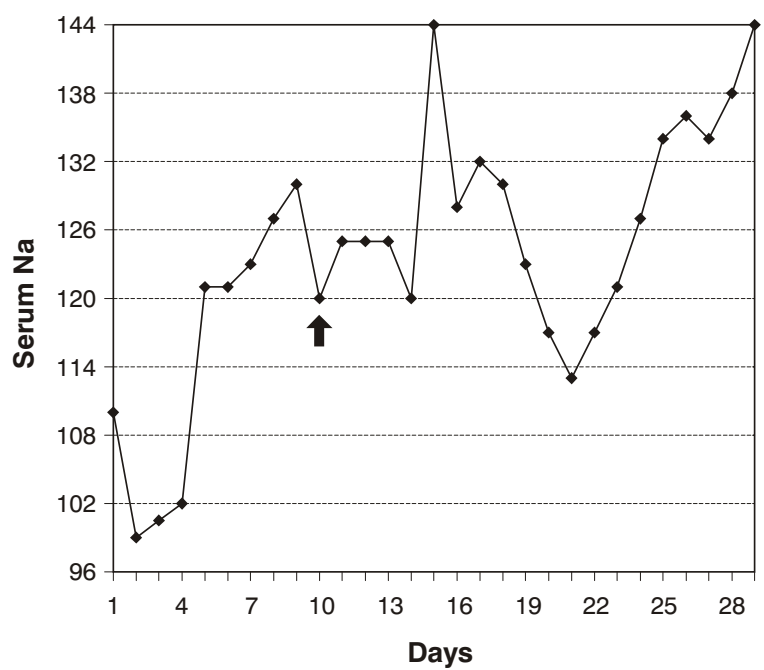

Figure 2 - Serum sodium levels (in $\mathrm{mEq} / \mathrm{l}$ ) during the patient's clinical course. The arrow shows onset of signs and symptoms of locked-in syndrome high, ${ }^{7}$ and even if serum sodium levels are corrected within safe limits. ${ }^{10-12}$ Experimental evidence suggests the chronicity of hyponatremia as a predisposing factor to myelinolysis. ${ }^{11}$ CPM and EPM may occur in isolation or combined. ${ }^{7-9,12}$ Central basis pontis is more susceptible to acute metabolic stress. 1,4,7

CPM was first described in alcoholic patients; afterwards, it was associated with electrolytic disorders, especially hyponatremia, and its risk increased in those patients submitted to rapid correction of hyponatremia. ${ }^{3-8,12}$ These findings resulted in some changes in the recommended management of hyponatremic patients. ${ }^{7,12}$

The patient described here had an excessively rapid correction of serum sodium deficiency, from 102 to $121 \mathrm{mEq} / \mathrm{I}$ in only 10 hours, which exceeds the safe limits, which should not be greater than $0.5 \mathrm{mEq} / \mathrm{l} / \mathrm{h} .7,8$ Both hypokalemia and the extremely low initial serum sodium level might have contributed to the tragic outcome.

The patient had neurological symptoms preceded by extremely severe hyponatremia, with abnormal renal function test results ever since her admission to the hospital of origin. On the 10th day at the hospital of origin she developed the typical locked-in syndrome, in which patients have mutism and quadriplegia with preserved sensitivity and level of consciousness. ${ }^{4}$ 
This disease is characterized by an extremely poor outcome, which is sometimes fatal. $1,5,6,8,12,15$ Best results have been reported to occur during childhood. ${ }^{8}$ Recovery may be spontaneous and progressive, sometimes without any neurological sequelae. 1,5,6,12 Some studies have described that lesions disappear, suggesting that CPM and EPM can be totally reversible. ${ }^{10}$

Apparently, there is no correlation between clinical signs and symptoms and the persistence of lesions on neuroimaging exams, 7,10,14 as well as between extent of lesions on MRI and clinical severity of subsequent presentation or clinical outcome. ${ }^{12,14}$ Abnormal radiological results may be found despite evident clinical improvement or after resolution of clinical symptoms, or else, they may resolve despite the presence of clinical neurological symptoms. ${ }^{7,12,14}$

In the medical literature, recommendations for the management of hyponatremia are controversial. In cases of acute symptomatic hyponatremia, Brown ${ }^{12}$ suggests that its daily correction should not exceed $8 \mathrm{mEq} / \mathrm{l}$. Karp \& Laureno ${ }^{5}$ recommend a correction limit of $10 \mathrm{mEq} / \mathrm{l}$ within the first 24 hours and $21 \mathrm{mEq} / \mathrm{l}$ in 48 hours. Pradhan et al. ${ }^{11}$ state that myelinolysis can be prevented by limiting the increase in serum sodium levels to $12 \mathrm{mEq} / \mathrm{l}$ in 24 hours or to $25 \mathrm{mEq} / \mathrm{l}$ in 48 hours. Brown \& Caruso 7 proposed a limit of $0.5 \mathrm{mEq} / \mathrm{l}$ per hour for serum sodium correction. Decaux \& Soupart ${ }^{13}$ recommend that in patients whose duration of hyponatremia is not established serum sodium increase should not exceed $10 \mathrm{mEq} / \mathrm{l} / 24 \mathrm{~h}$, particularly when there are risk factors for ODS.

Other authors found improvement of neurological symptoms with plasmapheresis, steroids, gamma globulins and thyrotropin-releasing hormone. $6,10,12,13$ Some authors used steroids to treat CPM; however, their results were controversial. 5,14

Based on a previous report that incipient CPM can be reversed by reinduction of hyponatremia, Oya et al. ${ }^{15}$ reinduced it in a patient with symptoms strongly suggestive of early-stage CPM, with resolution of neurological deficit. According to these authors, immediate reinduction of hyponatremia seems to be a safe treatment option, which improves prognosis after neurological deterioration secondary to rapid correction of hyponatremia. Decaux \& Soupart ${ }^{13}$ recommend reinduction as a preventive measure in patients submitted to rapid correction of serum sodium (greater than $15 \mathrm{mEq} / \mathrm{l} / 24 \mathrm{~h}$ without associated risk factors), either with or without early symptoms.
The present study highlights the importance of careful intravenous hydration of any children with electrolytic disorders, especially those who are acutely ill. ODS is a potentially fatal complication in several pediatric clinical situations, and its prevention depends on attention to patients' laboratory parameters and to careful correction of existing deficits.

\section{References}

1. Lilje CG, Heinen F, Laubenberger J, Krug I, Brandis M. Benign course of central pontine myelinolysis in a patient with anorexia nervosa. Pediatr Neurol. 2002;27:132-5.

2. Ruzek KA, Campeau NG, Miller GM. Early diagnosis of central pontine myelinolysis with diffusion-weighted imaging. Am J Neuroradiol. 2004;25:210-3.

3. Osborn AG, Hedlund GL, Blaser SI, Illner A, Salzman KL, Harnsberger HR, et al. Osmotic demyelination syndrome. In: Diagnostic imaging brain. Salt Lake City: Amirsys; 2004. p. I10.42-5.

4. Victor M, Ropper AH. The acquired metabolic disorders of the nervous system: central pontine myelinolysis. In: Victor $M$, Ropper AH. Adams and Victor's principles of neurology. 7th ed. New York: McGraw-Hill; 2001. p. 1193-5.

5. Laureno R, Karp BI. Myelinolysis after correction of hyponatremia. Ann Intern Med. 1997; 126:57-62.

6. Martin RJ. Central pontine and extra-pontine myelinolysis: the osmotic demyelination syndromes. J Neurol Neurosurg Psychiatry. 2004;75(suppl III):iii22-8.

7. Brown WD, Caruso JM. Extrapontine myelinolysis with involvement of the hippocampus in three children with severe hypernatremia. J Child Neurol. 1999;14:428-33.

8. Haspolat S, Duman O, Senol U, Yegin O. Extrapontine myelinolysis in infancy: report of a case. J Child Neurol. 2004;19:913-5.

9. Chua GC, Sitoh YY, Lim CC, Chua HC, Ng PY. MRI findings in osmotic myelinolysis. Clin Radiol. 2002;57:800-6.

10. Niehaus L, Kulozik A, Lehmann R. Reversible central pontine and extrapontine myelinolysis in a 16 -yeas-old girl. Childs Nerv Syst. 2001;17:294-6.

11. Pradhan S, Jha R, Singh MN, Gupta S, Phadke RV, Kher V. Central pontine myelinolysis following slow correction of hyponatremia. Clin Neurol Neurosurg. 1995;97:340-3.

12. Brown WD. Osmotic demyelination disorders: central pontine and extrapontine myelinolysis. Curr Opin Neurol. 2000;13:691-7.

13. Decaux G, Soupart A. Treatment of symptomatic hyponatremia. Am J Med Sci. 2003;326:25-30.

14. Menakaya JO, Wassmer E, Bradshaw K, Seri S, Whitehouse WP. Idiopathic central pontine myelinolysis in childhood. Dev Med Child Neurol. 2001;43:697-700.

15. Oya S, Tsutsumi K, Ueki K, Kirino T. Reinduction of hyponatremia to treat central pontine myelinolysis. Neurology. $2001 ; 57: 1931-2$

Correspondence:

Adriana Rocha Brito

Rua Joaquim Távora, 24/2003A, Icaraí

CEP 24230-540 - Niterói, RJ - Brazil

Tel.: +55 (21) $2710.0122,+55$ (21) 8781.7255

Fax: +55 (21) 2132.8080

E-mail: adrianarochabrito@ig.com.br 